\title{
Synthesis and Characterization of Water-Soluble
}

\section{Zn(II)-phthalocyanine-peptide Conjugates}

Martha Sibrian-Vazquez, ${ }^{1}$ Javier Ortiz, ${ }^{2}$ Irina V. Nesterova, ${ }^{1}$ Fernando Fernández-Lázaro, ${ }^{2}$ Angela Sastre-Santos, ${ }^{2}$ Steven A. Soper, ${ }^{1}$ and M. Graça H. Vicente ${ }^{I, *}$

E-mail : vicente@1su.edu

Contents:

NMR data........................................... 1

Absorption/emission data............................p 2

HPLC traces..................................... 6

MALDI-TOF data................................. 7 
NMR data:

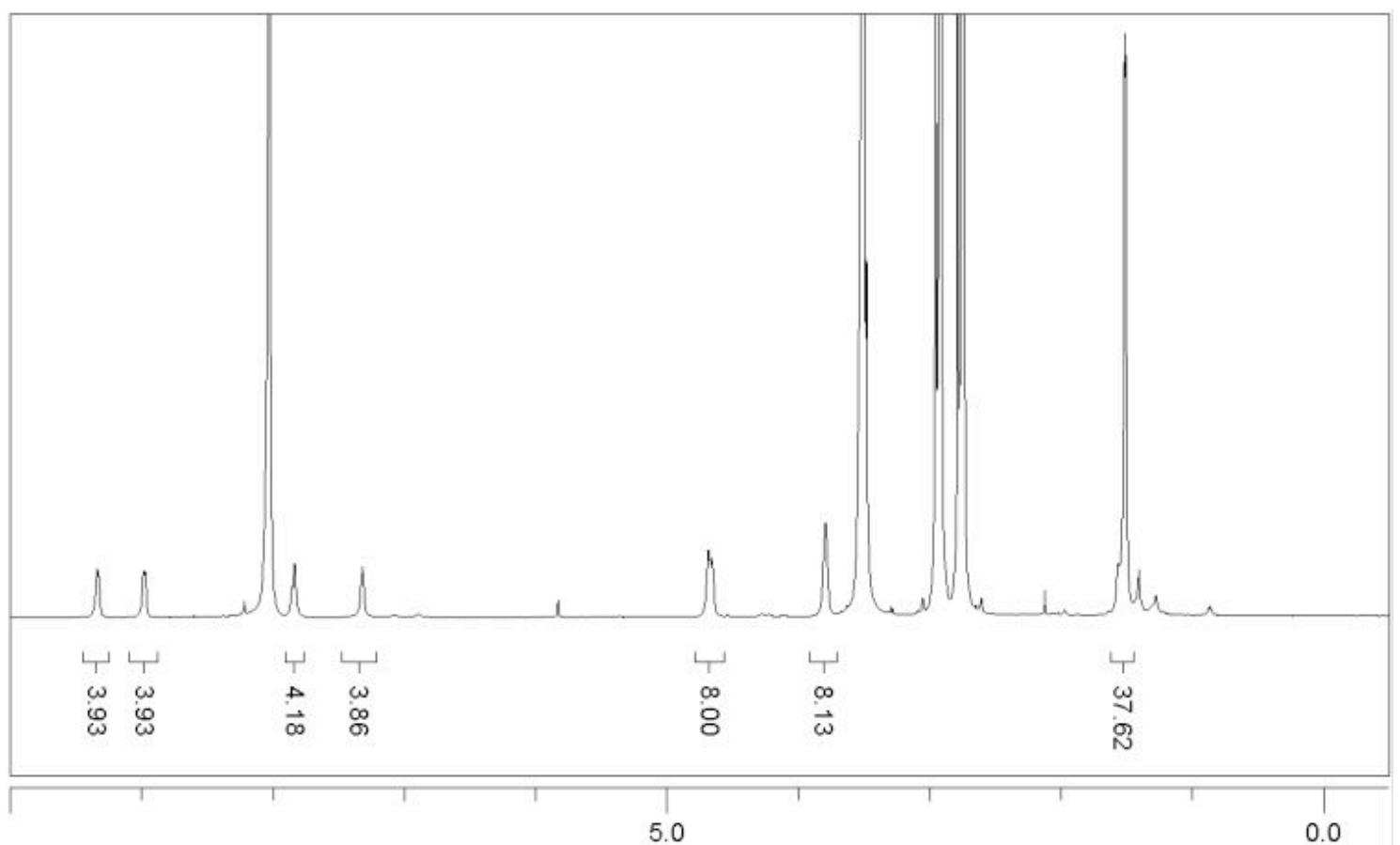

Figure S1: ${ }^{1} \mathrm{H}-\mathrm{NMR}$ spectrum $\left(\mathrm{DMF}-d_{7}\right)$ of $\mathrm{Pc} 1$

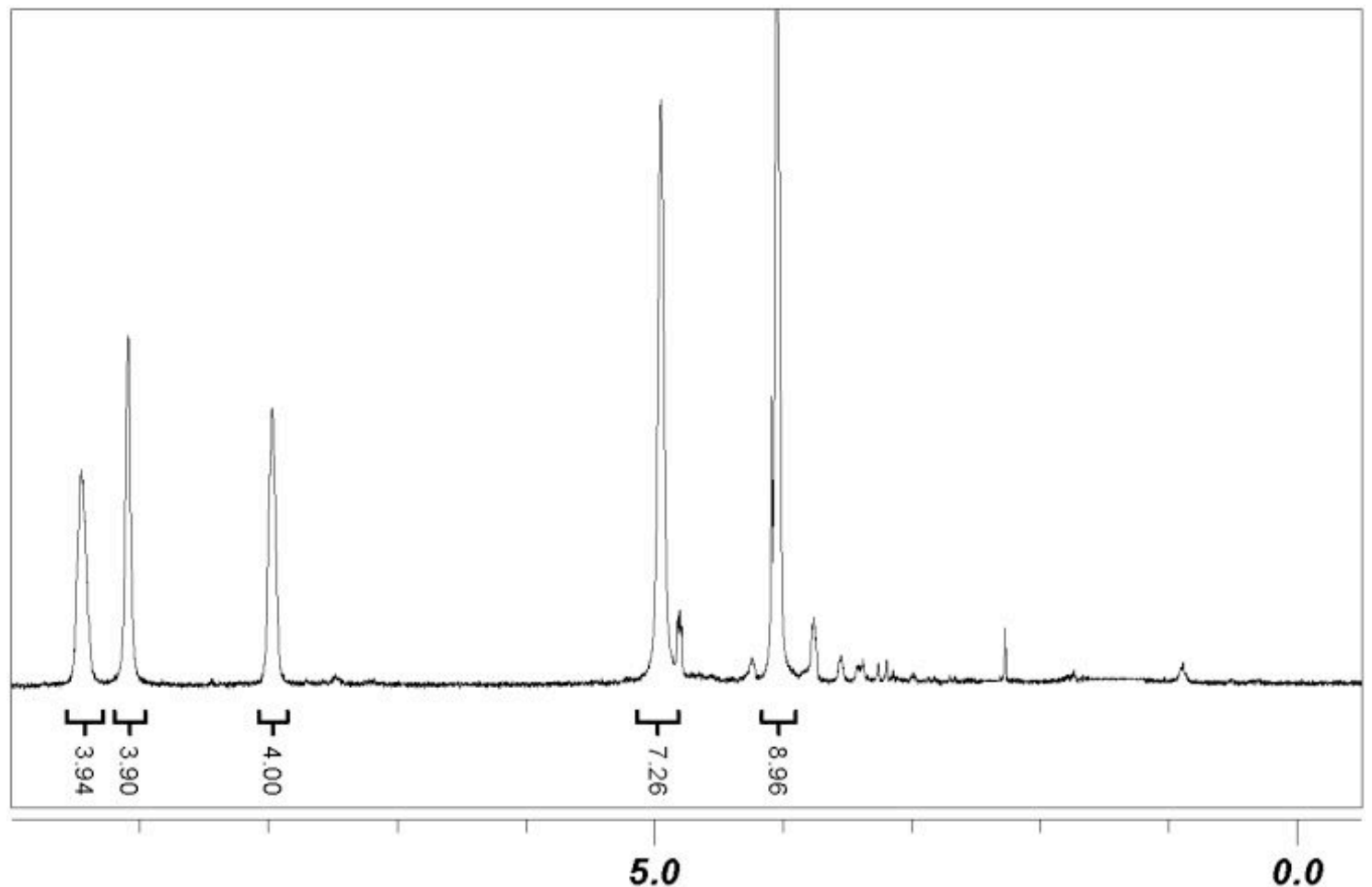

Figure S2: ${ }^{1} \mathrm{H}-\mathrm{NMR}$ spectrum $\left(\mathrm{TFA}-d_{1}\right)$ of Pc 2 
UV-Vis Data:

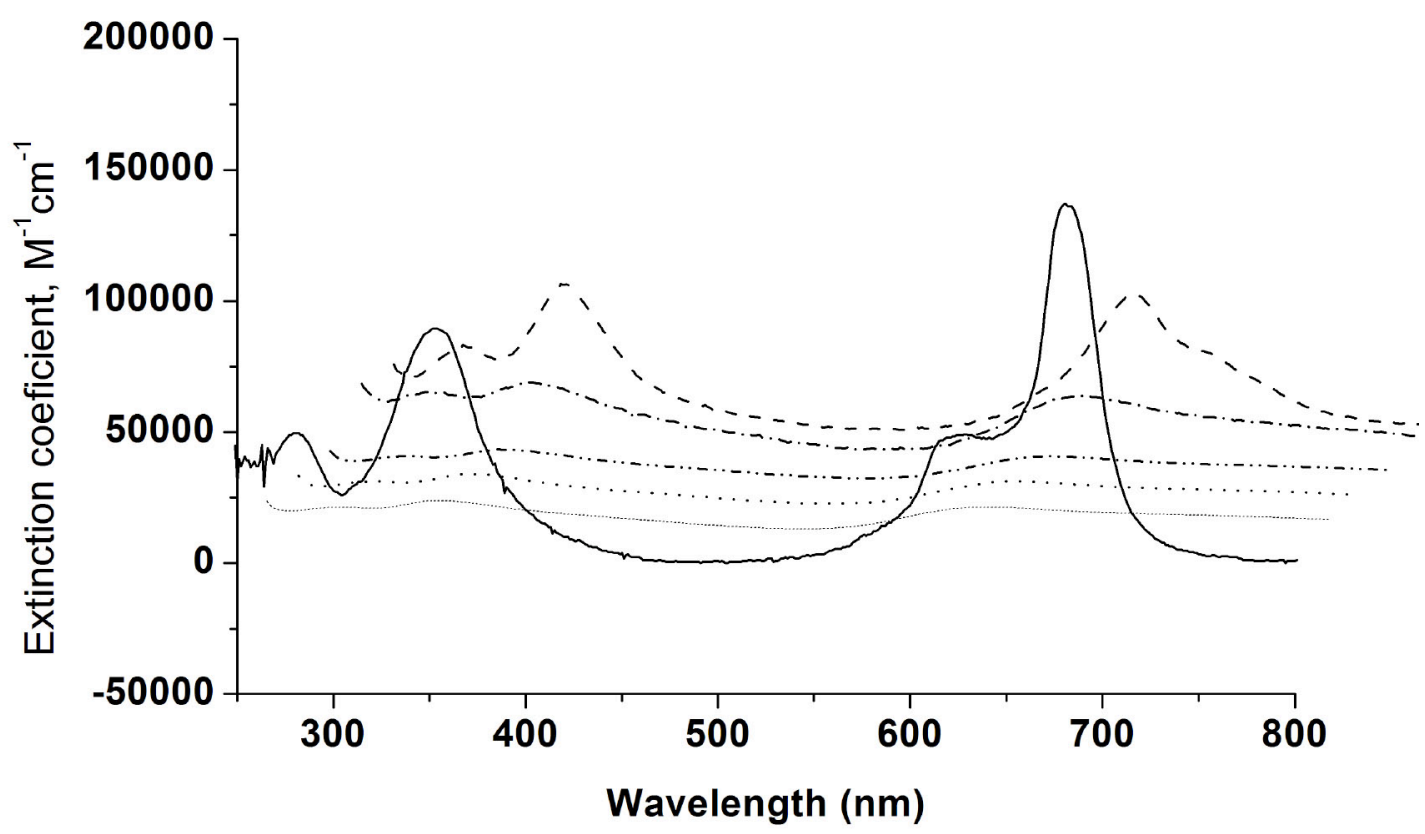

Figure S3. Absorption spectra of Pc $\mathbf{2}$ in $100 \mathrm{mM}$ phosphate buffer at different $\mathrm{pH}$ and in DMSO. DMSO (full line), pH 5.00 (dash line), pH 6.00 (dash-dot-dash), pH = 7.00 (dashdot-dot-dash), $\mathrm{pH}=7.4$ (dot), $\mathrm{pH}=8.00$ (short dash).

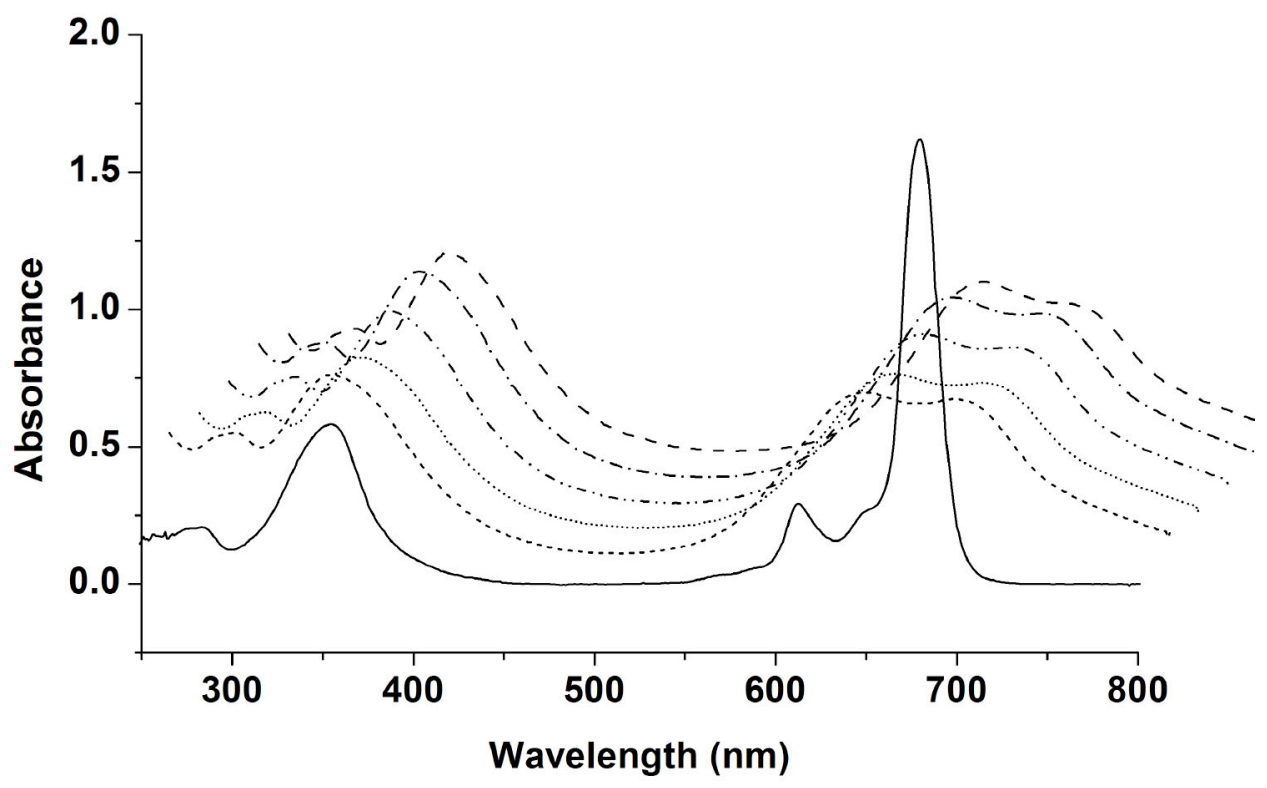

Figure S4. Absorption spectra of Pc 3b in $100 \mathrm{mM}$ phosphate buffer at different $\mathrm{pH}$ and in DMSO. DMSO (full line), pH 5.00 (dash line), pH 6.00 (dash-dot-dash), pH = 7.00 (dashdot-dot-dash), $\mathrm{pH}=7.4$ (dot), $\mathrm{pH}=8.00$ (short dash). 


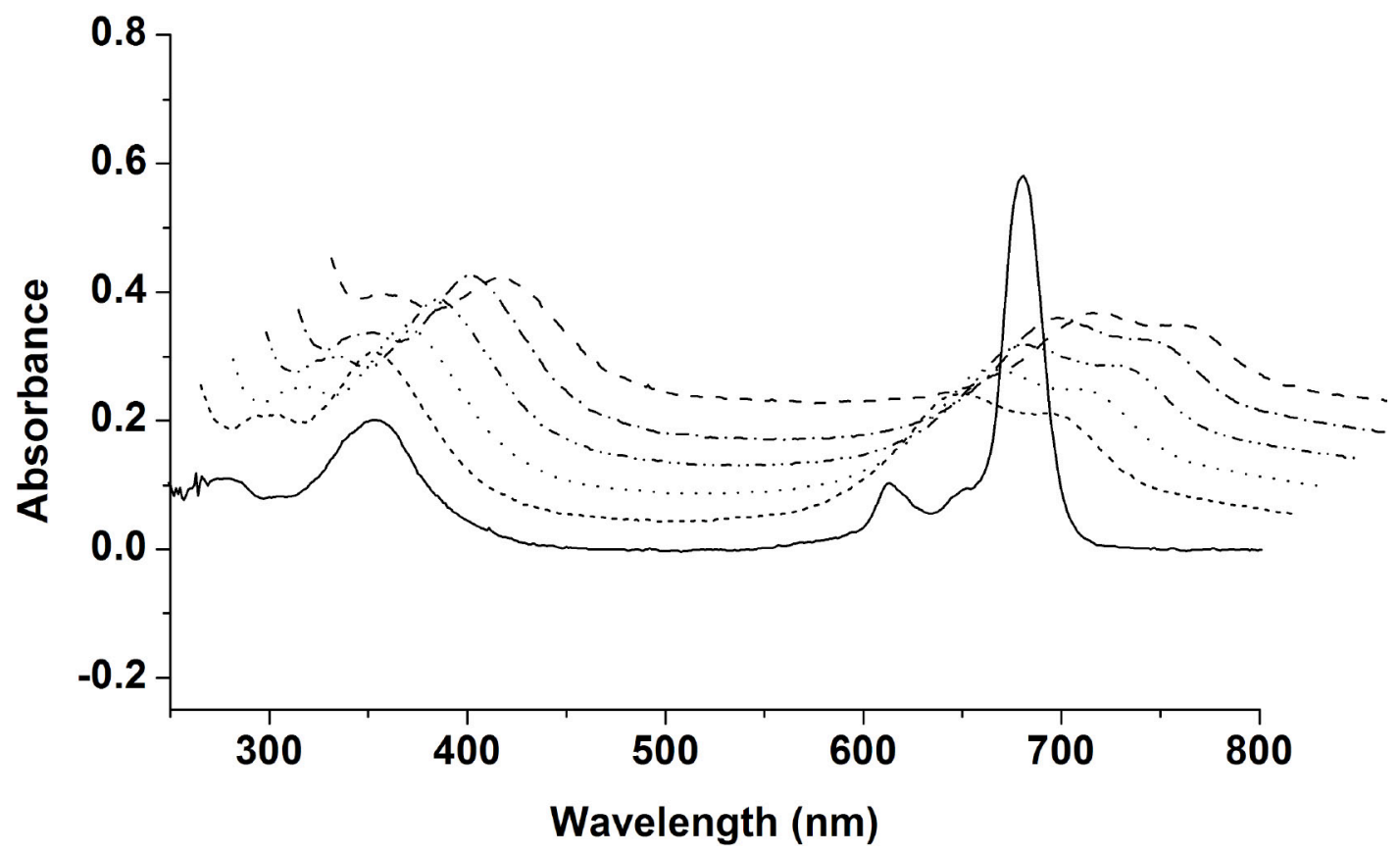

Figure S5. Absorption spectra of Pc conjugate 5 in $100 \mathrm{mM}$ phosphate buffer at different $\mathrm{pH}$ and in DMSO. DMSO (full line), $\mathrm{pH} 5.00$ (dash line), $\mathrm{pH} 6.00$ (dash-dot-dash), $\mathrm{pH}=7.00$ (dash-dot-dot-dash), $\mathrm{pH}=7.4$ (dot), $\mathrm{pH}=8.00$ (short dash).

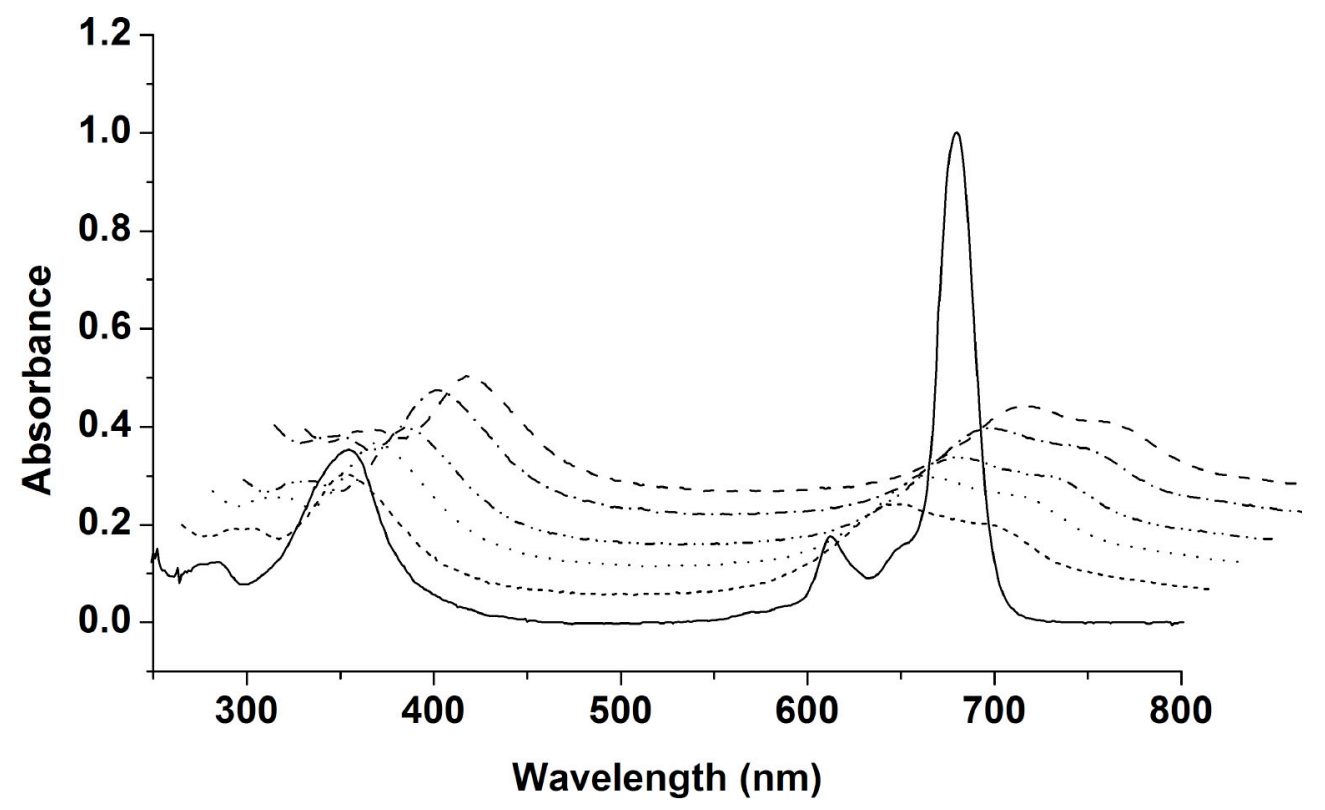

Figure S6. Absorption spectra of Pc conjugate 6 in $100 \mathrm{mM}$ phosphate buffer at different $\mathrm{pH}$ and in DMSO. DMSO (full line), $\mathrm{pH} 5.00$ (dash line), $\mathrm{pH} 6.00$ (dash-dot-dash), $\mathrm{pH}=7.00$ (dash-dot-dot-dash), $\mathrm{pH}=7.4$ (dot), $\mathrm{pH}=8.00$ (short dash). 


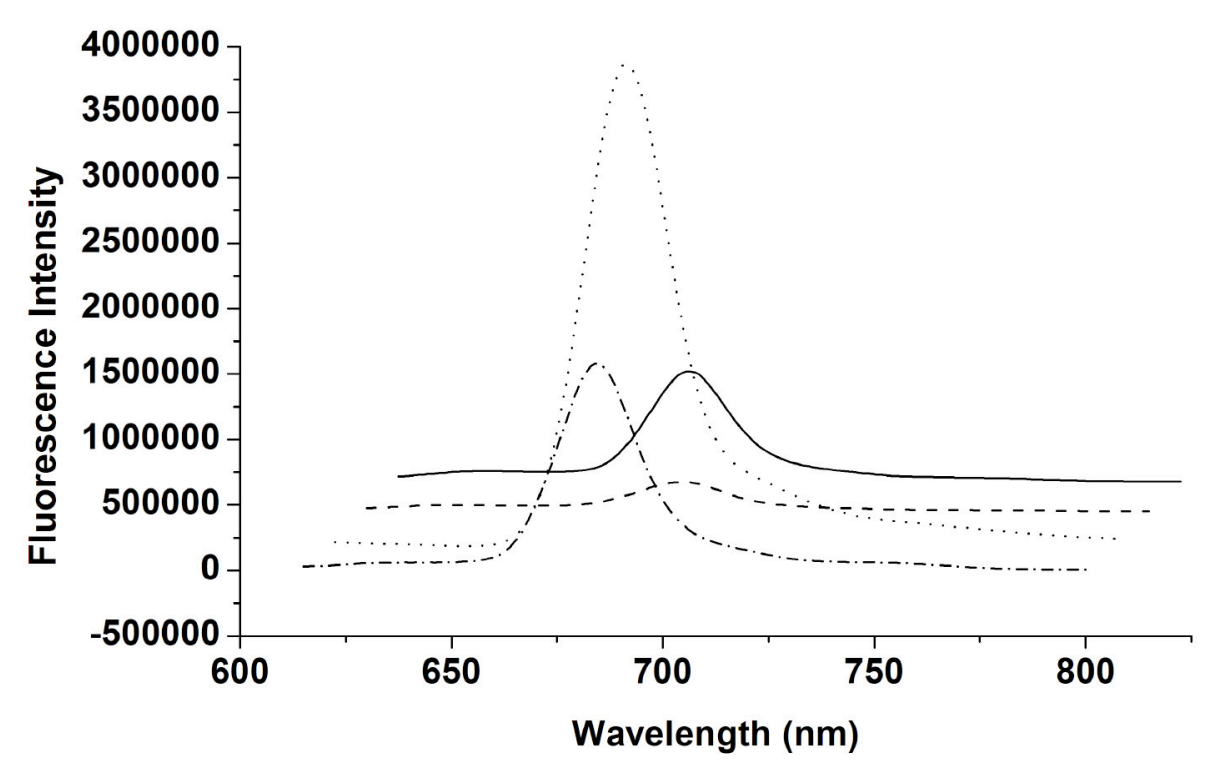

Figure S7. Fluorescence emission spectra of Pc 2 (dash), exc. 605 nm; Pc 3b (full line), exc. $605 \mathrm{~nm}$; Pc conjugate 5 (dot), exc. $650 \mathrm{~nm}$; Pc conjugate 6 (dash-dot-dash), exc. $605 \mathrm{~nm}$ in DMSO.

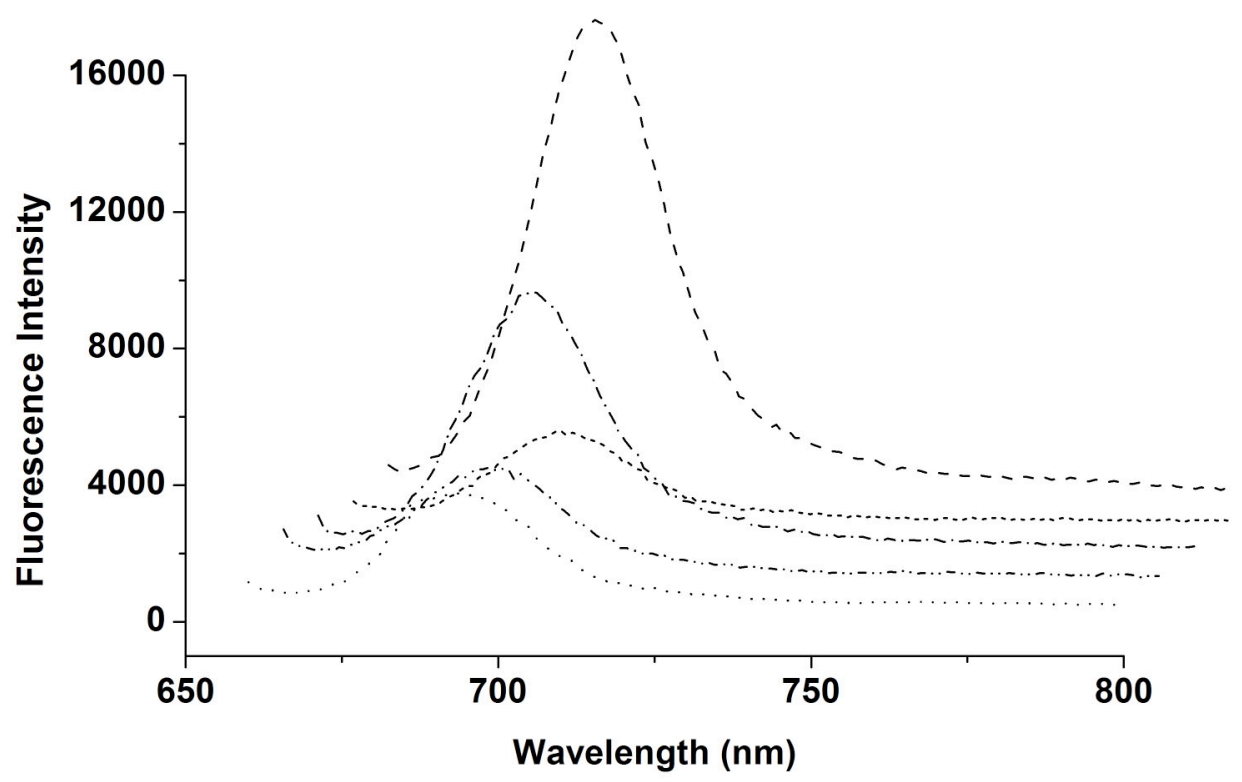

Figure S8. Fluorescence spectra of Pc conjugate 5 in $100 \mathrm{mM}$ phosphate buffer at different pH; pH 5.00 (dash line), pH 6.00 (dash-dot-dash), $\mathrm{pH}=7.00$ (dash-dot-dot-dash), $\mathrm{pH}=7.4$ (dot), $\mathrm{pH}=8.00$ (short dash). Excitation wavelength $650 \mathrm{~nm}$. 


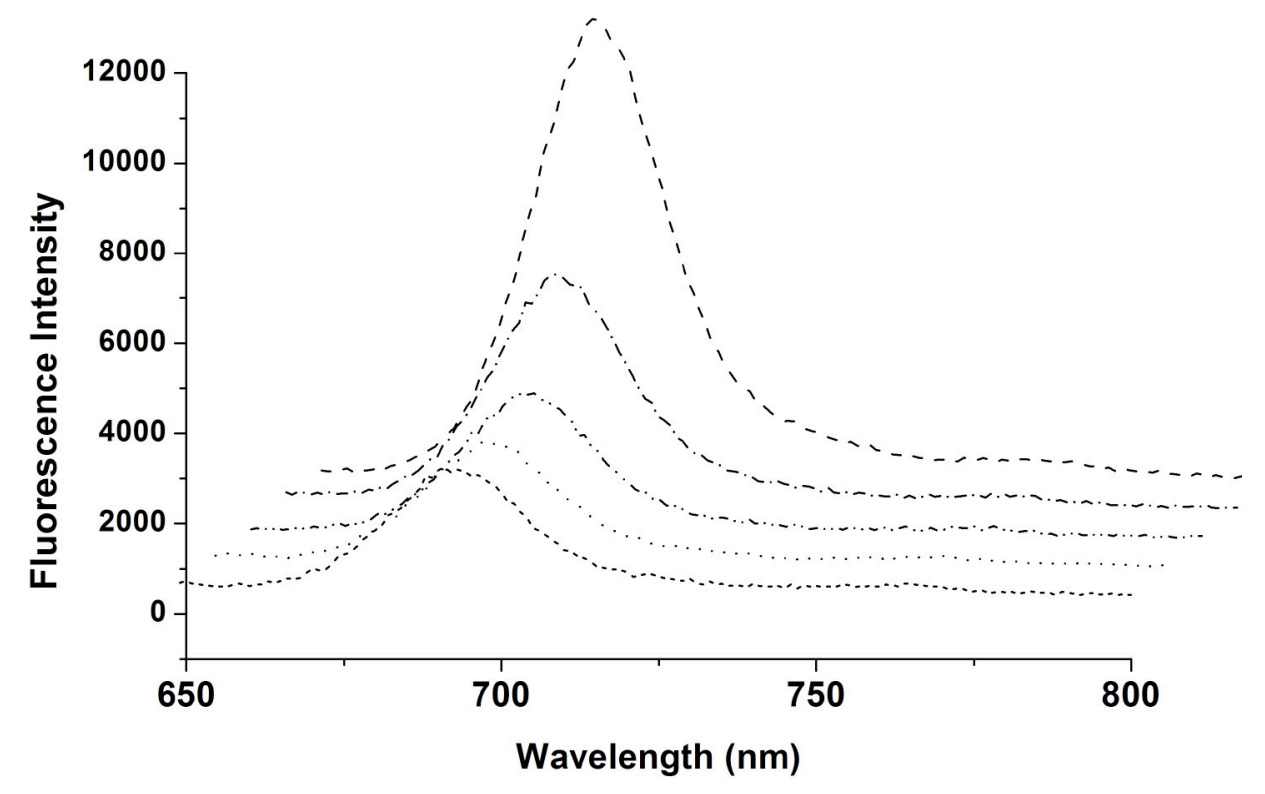

Figure S9. Fluorescence spectra of Pc conjugate 6 in $100 \mathrm{mM}$ phosphate buffer at different pH; pH 5.00 (dash line), pH 6.00 (dash-dot-dash), pH = 7.00 (dash-dot-dot-dash), $\mathrm{pH}=7.4$ (dot), $\mathrm{pH}=8.00$ (short dash). Excitation wavelength $605 \mathrm{~nm}$.

HPLC traces:

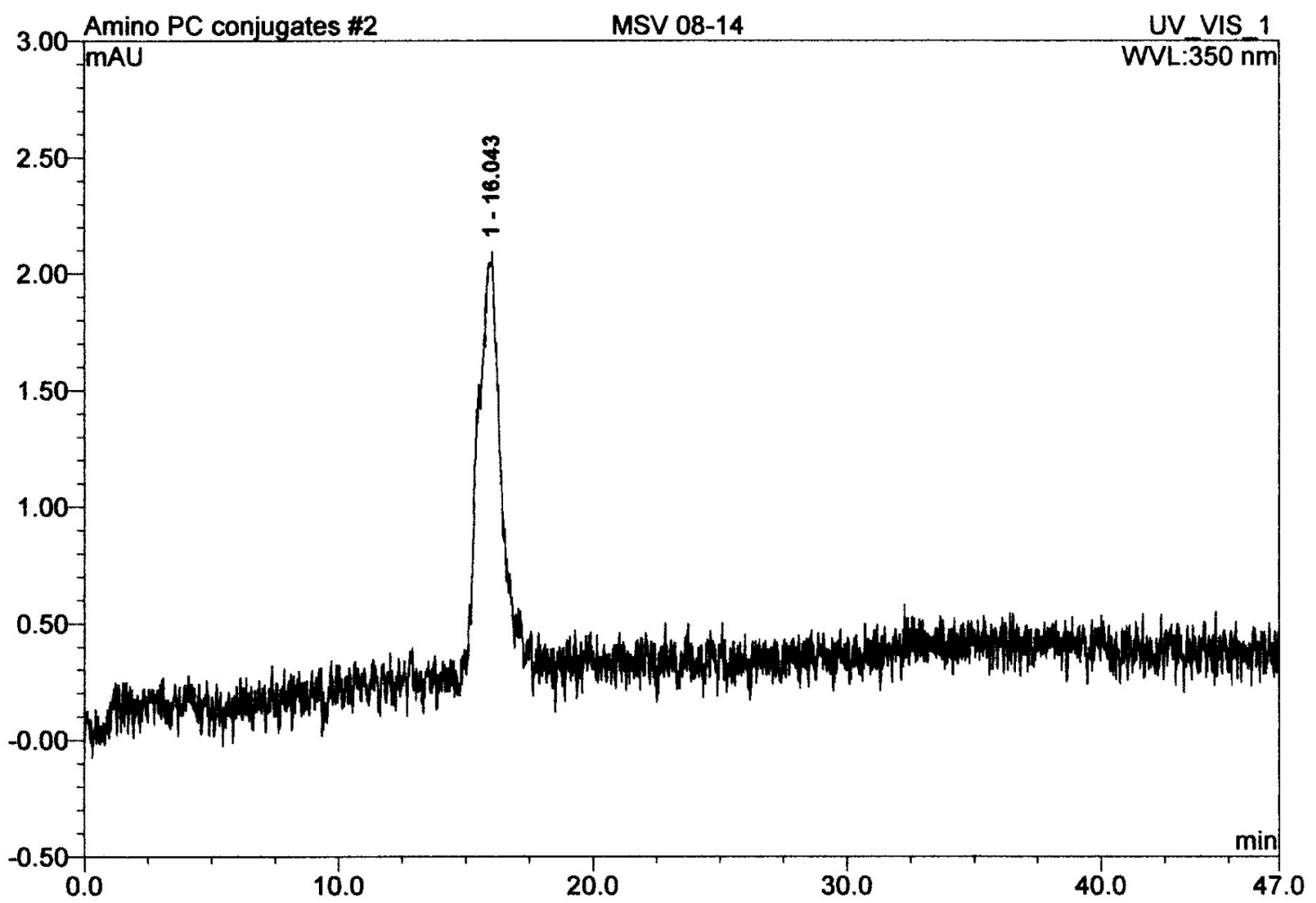

Figure S10. HPLC trace of Pc conjugate 5. Column: Delta Pak $C_{18} 300 \AA, 5 \mu \mathrm{m}, 3.9 \times 150$ $\mathrm{mm}$ (Waters, USA); flow rate $1 \mathrm{~mL} / \mathrm{min}$; injected volume $20 \mu \mathrm{L}$; wavelength detection: 350 nm. Stepwise gradient from $50 \%$ solvent B to $95 \%$ solvent B. Solvent A: $5 \%$ acetonitrile, $0.1 \%$ TFA, $\mathrm{H}_{2} \mathrm{O}$. Solvent B: $5 \% \mathrm{H}_{2} \mathrm{O}, 0.1 \%$ TFA, acetonitrile 


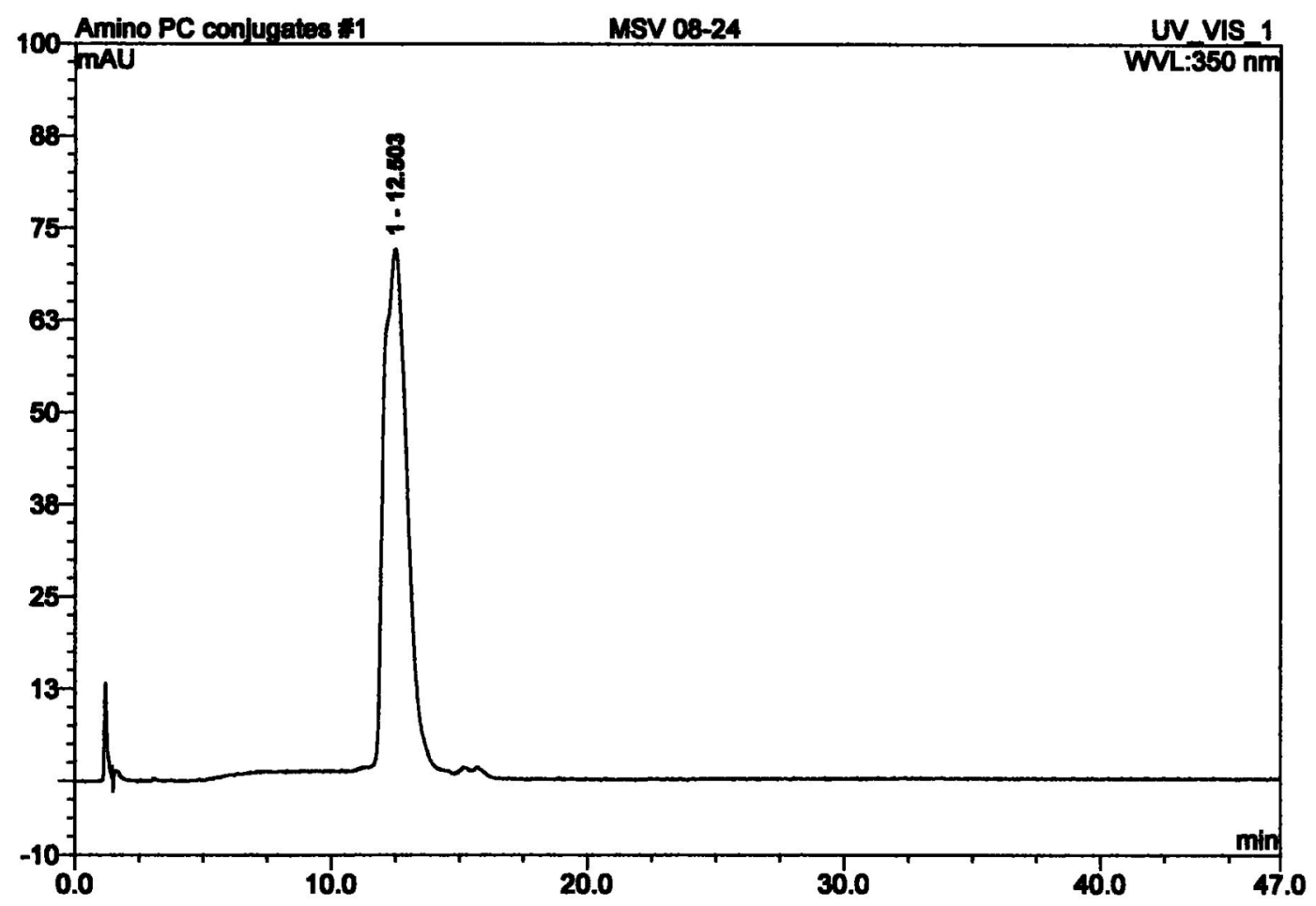

Figure S11. HPLC trace of Pc conjugate 6. Column: Delta Pak $\mathrm{C}_{18} 300 \AA, 5 \mu \mathrm{m}, 3.9 \times 150$ $\mathrm{mm}$ (Waters, USA); flow rate $1 \mathrm{~mL} / \mathrm{min}$; injected volume $20 \mu \mathrm{L}$; wavelength detection: 350 $\mathrm{nm}$. Stepwise gradient from $50 \%$ solvent B to $95 \%$ solvent B. Solvent A: $5 \%$ acetonitrile, $0.1 \%$ TFA, $\mathrm{H}_{2} \mathrm{O}$. Solvent B: $5 \% \mathrm{H}_{2} \mathrm{O}, 0.1 \%$ TFA, acetonitrile

\section{MALDI-TOF Spectra:}

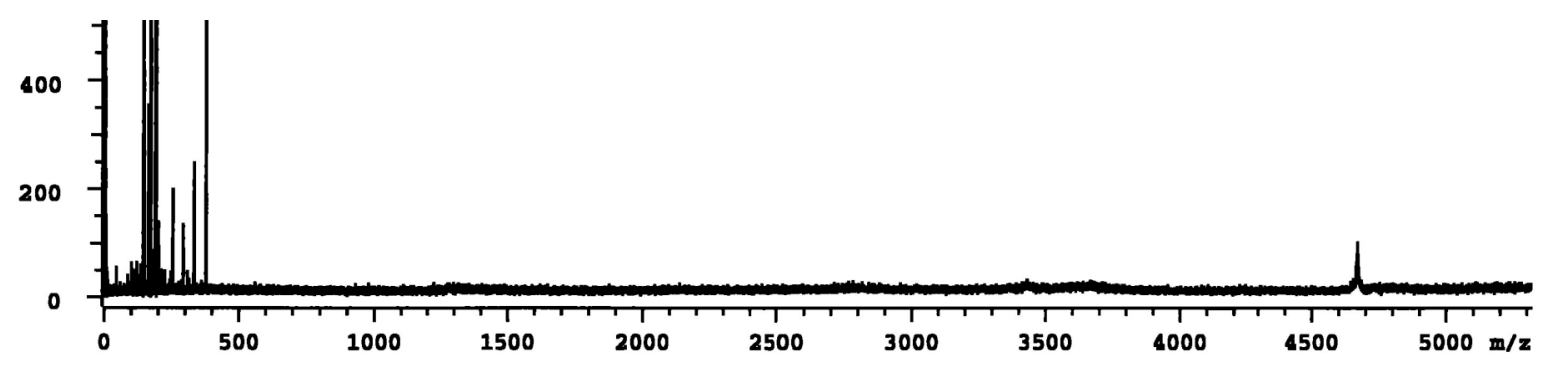

Figure S12. MALDI-TOF spectra Pc conjugate 5. $m / z 4670.643\left(\mathrm{M}+\mathrm{H}^{+}\right)$.

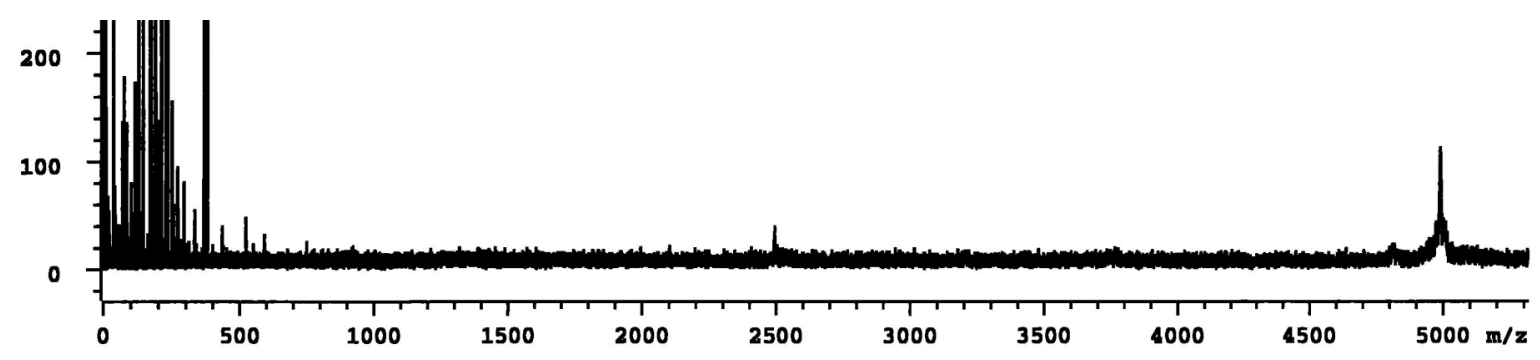

Figure S13. MALDI-TOF spectra Pc conjugate 6. $\mathrm{m} / \mathrm{z} 4995.527\left(\mathrm{M}+\mathrm{Na}^{+}\right), 2496.566(\mathrm{M}+$ $\left.\mathrm{Na}^{+}+2 \mathrm{H}^{+}\right)$. 